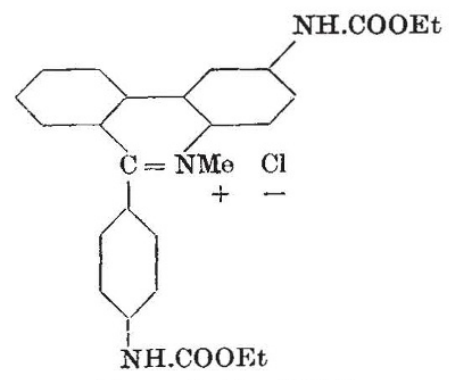

Formula I. S1544

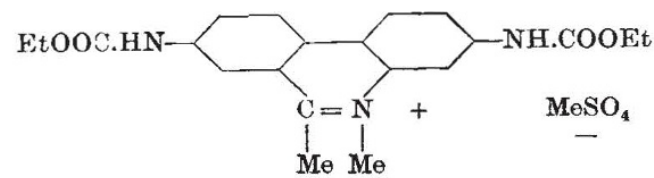

Formula II. S1582

The fact that cured animals and also those showing suppreszion of infection failed to develop an obvious infection when reinoculated, even many months later, indicates that with this trypanosome immunity phenomena play a considerable part in conducing to the therapeutic effect. But treatment is more successful at an early stage of the infection than later, when parasites are numerous in the blood, of the infour in this respect differing from that with $T$. congolense $e^{3,4}$, The results in the case of the higher range of dosage both of the phenanthridine compounds and Bayer $7602(A C)$ are highly signiflcant. (We are indebted to Dr. R. A. Robb, Mathematics Department, University, Glasgow, for statistical information on this point.)

The above phenanthridine compounds which influence $T$. cruzi infections do not act on $T$. brucei or $T$. comgolense except in high doses. Others of the phenanthridine series have also shown some chemotheraOthers of the ph $T$ cruzi ${ }^{\circ}$ and the relations between such action peutic influence on $T$. cruzi, and discussed in a later publication. The and chemical constitution wilue on the intracellular stage of the parasite question of possible inf.

The biological part of this work has been done with the support of the Medical Research Council.

C. H. BROWNING.

M. M. CAIVER.

Bacteriology Department,

University, Glasgow.

L. P. WALIS.

Department of Scientific and Industrial Research,

Chemical Research Laboratorv

$$
\begin{gathered}
\text { Teddington, Mid } \\
\text { Dec. } 14 .
\end{gathered}
$$

${ }^{1}$ Walls, L. P., Brit. Prov. Spec. Nos. $14478 / 43,52 / 44$ and 53/44. 2 Fulton, J. D., Ann. Trop. Med., 37, 164 (1943)

- Browning, C. H., and Calver, K. M., J. Path. Bact., 55, 393 (1943).

4 Calver, K. M., Trop. Dis. Bull., 42, 704 (1945).

\section{Production of Diphtheria Toxin by the Submerged Culture Method}

THF success which has attended the submerged culture method for the production of penicillin has led us to inquire into the possibilities of producing diphtheria toxin by similar methods. The flrst step was to see if diphtheria toxin could be produced in flasks which were continually shaken so as to obtain growth throughout the medium instead of merely on the surface.

We took, therefore, our rourine papain digest broths and weak tryptic digest broths prepared essentially as described by Pope and Linggood ${ }^{1}$ and sterilized them in $300 \mathrm{ml}$. amounts in one-litre conical linggood, and sterilized them inlated with our routine strain of $C$. flasks. They were thon inoculated diphtherice (Park Williams No. whereby the contents of the flasks weratery 140 oscillaticns per minute. Proliflc growth occurred throughout the medium and, after four days growth, 30-40 units per ml. of diphtheria toxin were found to be present in the culture filtrates when tested by the usual flocculation test. The $p H$ of such filtrates was, however, abnormally high, being often $\theta$ or greater. Therefore in subsequent experiments we added much more maitose to our broths, namely, 0.9 per cent instead of our usual .3 per cent, and found growth and toxin production to be greater and the $p H$ filtrates to be more normal. On a weak tryptic digest broth (total nitrogen content of $3.0 \mathrm{mgm}$. per ml., maitose content of 0.9 per cent) we have obtained 50 units per ml. of diphthe

shaking cultures. This fact strongly suggests that, as is the case with penicillin, large-
scale production of many bacterial toxins may be carried out much scale production of many bacterial toxins may be carried out much
more conveniently and much more quickly by submerged culture more con
methods.

Wellcome Physiological Research Laboratories, F. V. LINGGOOD. Beckenham, Kent. Oct. 26 .

'Pope, C. G., and Linggood, F. V., Brit. J. Exp. Path., 20, 297 (1939).
Absorption Spectra of the Exocrine Cells of the Pancreas

Is 1941 Caspersson, Landström-Hyden and Aquilonius demonstrated that the chromidial substance contained in the pancreatic exocrine cells and in other serous secreting elements had a typical absorption spectrum in the ultra-violet region with a peak in $2600 \mathrm{~A}$. As this substance showed a negative Feulgen reaction, they concluded that it is a nucleoprotein with a high content of nucleotides of ribonucleic type. In the apical part of the cell containing the granules, they found absorption curves of a protein type, but with a concentration much lower than in the basal zone; they explain this difference as due to the dilution of the secretion.

I used an ultra-violet microscope with a monochromator similar to that described by Gersh and Baker ${ }^{2}$ to re-examine the results obtained by Caspersson et al.; the absorption was determined microphotometrically on especially calibrated plates. Details of the technique and full description of the results are reported elsewhere ${ }^{8}$.

I wish to refer here particularly to the differences observed in the absorption curves of the apical zone of the pancreatic cells as compared with the results of Caspersson et al.

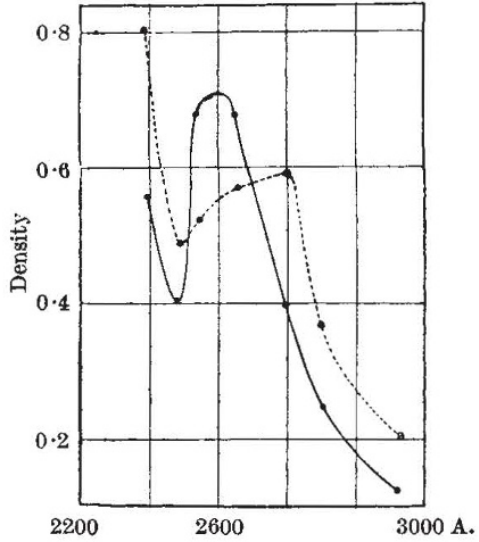

Fig. 1. ULTRA-VIOLET ABSORPTION CURVES OF A FRHEZE-DRIED AND DENATURED SEOTION, $3 u$ THICK, OF GUINEA PIG PANCREAS. Full line : absorption curve of the basal part of an exocrine cell (cytoplasm containing chromidial substance). Broken line : containing zymogenic granules'.

As seen in Fig. 1, the basal part of the cytoplasm of the pancreatic cell contains a substance with a maximum absorption at 2600 A., corresponding to the nucleotides. The cytological distribution of this portion of the cell corresponds exactly to the location of the chromidial substance. That these nucleotides are of the ribonucleic type was determined not only by the finding of a negative Feulgen reaction but also by digestion with the crystalline ribonuclease of Kunitz ${ }^{4}$ which hydrolyses specifically the ribonucleic acid and thus causes the disappearance of all the basophile staining substances of the cell. (I wish to express my thanks to Dr. M. Kunitz for supplying me with the crystallized nuclease.)

The apical zone containing zymogenic granules gives the typical curve of a protein with intense absorption in $2400 \mathrm{~A}$. and $2800 \mathrm{~A}$. These maxima are much higher than in the basal zone. From this

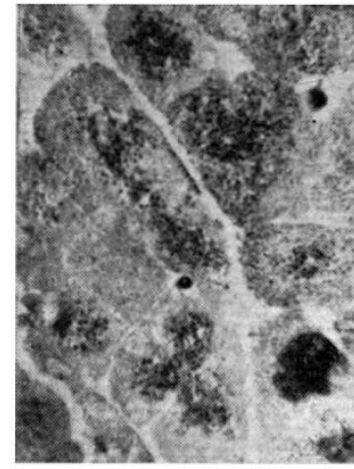

Fig. 2.

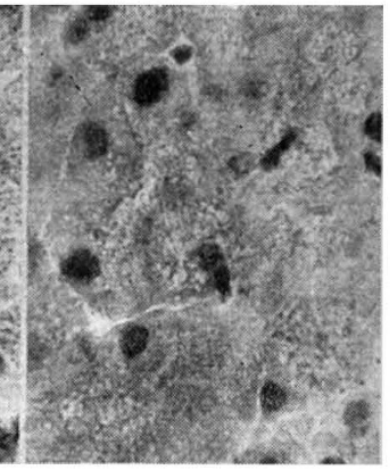

Fig. 3.
Fig. 2. FREERE-DRIED DENATURED SECTION OF THE PANCREAS OF A WhITE MOUSE; STAIN : IRON h EMATOXYLIN. (OB. 90, oc. 6, CL. 55.)

Fig. 3. FREE'T-DRIED SECTION OF THE PANCREAS OF A WHITE MOUSE TREATED FOR AN HOUR WITH GLYOEROL AND AFTERWARDS DENATURED. THE ZYMOGENIC GRANULES ARE DISSOLVED. STAIN : IRON HÆMATOXYIIN. 